\title{
Arteterapia: a Arte como Instrumento no Trabalho do Psicólogo
}

\author{
Art Therapy: Art as an Instrument \\ in the Work of the Psychologist \\ Arte Terapia: el Arte como Instrumento \\ en el Trabajo del Psicólogo
}
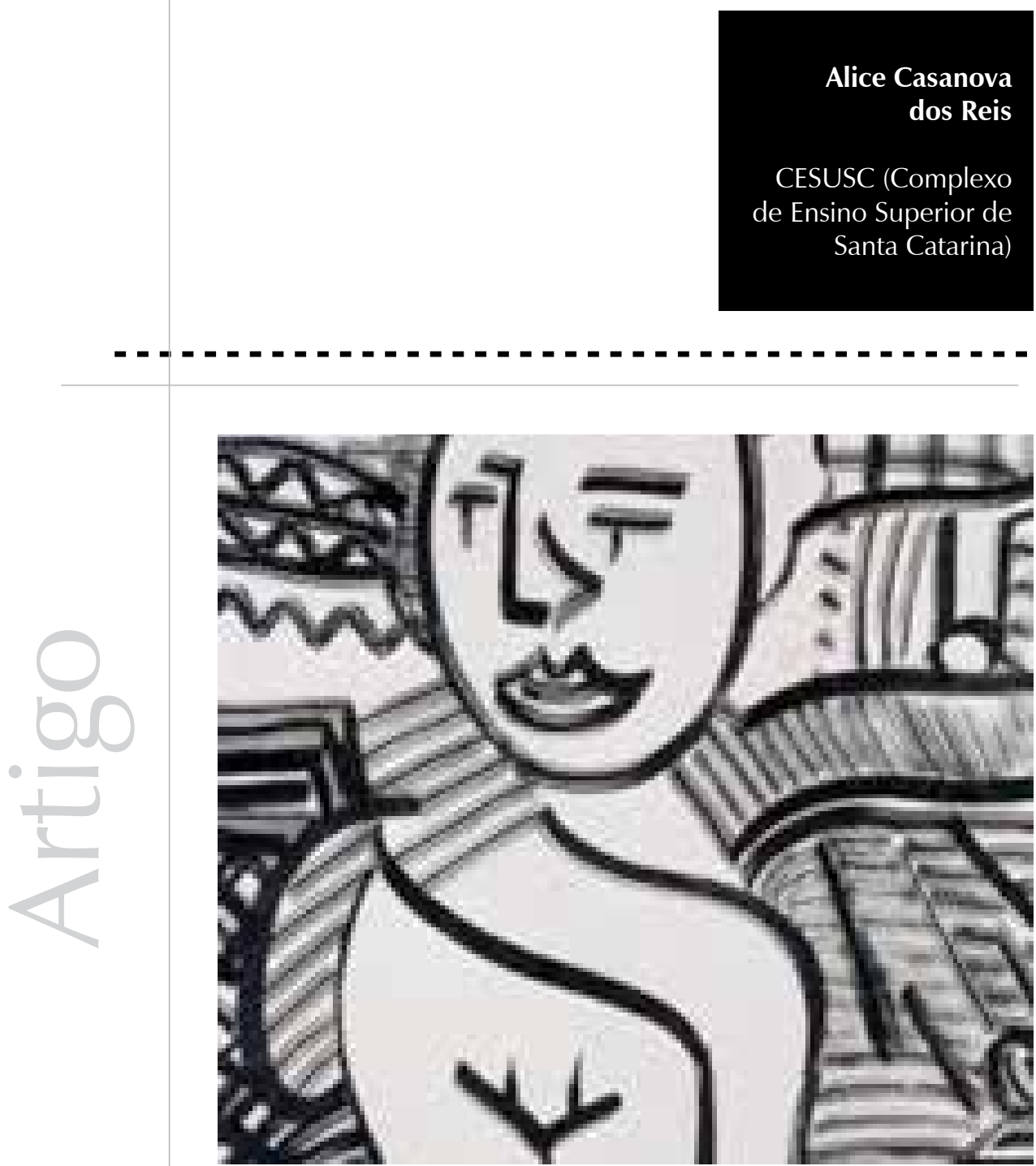
Resumo: A arteterapia é um método baseado no uso de várias formas de expressão artística com uma finalidade terapêutica. O presente artigo aborda a arteterapia tendo como objetivo refletir sobre a arte como instrumento de trabalho no campo específico da Psicologia. Apoiando-se na revisão de literatura sobre a temática, o artigo parte de um olhar histórico, examinando o contexto em que a arteterapia surge e seu desenvolvimento no Brasil. A seguir, são analisados os pressupostos fundamentais que norteiam o psicólogo nessa prática, assim como os aspectos conceituais e metodológicos próprios a cada uma das abordagens principais em arteterapia: psicanalítica, junguiana e gestáltica. A reflexão desenvolvida mostra que, apesar das diferentes molduras teóricas, a arteterapia é perpassada por uma concepção estética do humano, visto como um ser criativo, capaz de se transformar em artista da própria vida. Conclui-se, então, que a arte pode ser uma ferramenta valiosa para a atuação do psicólogo nos mais diferentes contextos, vinculada ao seu compromisso ético de contribuir para que o sujeito se (re)constitua como autor da própria história.

Palavras-chave: Arte-terapia. Psicanálise. Psicologia junguiana. Gestalt-terapia.

Abstract: Art therapy is a method based on the use of various forms of artistic expression for therapeutic purposes. This article approaches art therapy aiming to think about art as a working tool specifically in the field of psychology. Based on current literature review of the subject, our starting point was an historical outlook in order to examine the context in which art therapy emerges and evolves in Brazil. Following that, fundamental notions that guide the psychologist in this practice are analyzed, as well as the conceptual and methodological aspects specific to each one of the main approaches in art therapy: psychoanalytical, jungian and Gestalt. This reflection lead us to think, despite the different theoretical frames, that art therapy is pervaded by a conception of human aesthetics, seeing the person as a creative being, and capable of becoming his own life's artist. The conclusion is that art can be a valuable tool for psychologists in many different contexts, in connection to the ethical commitment of contributing to the subject so that he/she can (re)constitute him/herself as the author of his/her own history.

Keywords: Art therapy. Psychoanalysis. Junguian psychology. Gestalt therapy.

Resumen: El arte terapia es un método basado en el uso de varias formas de expresión artística con la finalidad terapéutica. El presente artículo aborda el arte terapia con el objetivo de reflexionar sobre el arte como un instrumento de trabajo en el campo específico de la psicología. El estudio se apoya en la revisión de la literatura y una visión histórica sobre la temática, se examina el contexto en que el arte terapia surge y desarrolla en Brasil. A seguir los análisis de los presupuestos fundamentales para el psicólogo en la práctica, también los aspectos conceptuales y metodológicos propios para cada uno de los abordajes principales en arte terapia: psicoanalítica, junguiana y gestáltica. La reflexión sobre el tema muestra que, a pesar de los diferentes marcos teóricos el arte terapia pasa por una concepción estética del humano, visto como un ser creativo, capaz de transformarse en el artista de su propia vida. Se concluye que el arte puede ser una herramienta valiosa en la actuación del psicólogo en los diferentes contextos, vinculado al su compromiso ético de contribuir para que el sujeto se (re)construya como el autor de su propia historia.

Palabras clave: Arte terapia. Psicoanálisis. Psicología junguiana. Terapia Gestalt.

Arteterapia é uma área de atuação profissional que utiliza recursos artísticos com finalidade terapêutica (Carvalho, 1995). Na definição da Associação Brasileira de Arteterapia1, "é um modo de trabalhar utilizando a linguagem artística como base da comunicação clienteprofissional. Sua essência é a criação estética e a elaboração artística em prol da saúde". Conforme delimita a Associação, a arteterapia é uma especialização destinada a profissionais com graduação na área da saúde, como Psicologia, Enfermagem e Fisioterapia, embora se reconheça sua utilização por pessoas formadas nas áreas das artes e da educação, desde que sem o enfoque clínico. a promoção da saúde e a qualidade de vida, abrangendo hoje as mais diversas linguagens: plástica, sonora, literária, dramática e corporal, a partir de técnicas expressivas como desenho, pintura, modelagem, música, poesia, dramatização e dança. Tendo em vista a formação do profissional e o público com o qual trabalha, a arteterapia encontra diferentes aplicações: na avaliação, prevenção, tratamento e reabilitação voltados para a saúde, como instrumento pedagógico na educação e como meio para o desenvolvimento (inter) pessoal através da criatividade em contextos grupais. Desse modo, o campo de atuação da arteterapia tem se ampliado, abrangendo além do contexto clínico também o educacional, o comunitário e o organizacional. No entanto, 
Entre os anos 20-30, as teorias de Freud e Jung trouxeram as bases para o desenvolvimento inicial da arteterapia como campo específico de atuação, segundo descrevem Carvalho e Andrade (1995). o desenvolvimento da arteterapia como área específica de trabalho deu-se na Psicologia, ligado primordialmente à questão da saúde mental, como veremos adiante.

O objetivo do presente artigo é justamente refletir sobre a arte como uma ferramenta de trabalho do psicólogo, contextualizando historicamente a arteterapia, discutindo os pressupostos fundamentais que sustentam esta prática e apresentando suas principais abordagens teóricas. Este trabalho vem contribuir no sentido de mostrar um panorama geral acerca da arteterapia, que permitirá a estudantes e a psicólogos conhecer uma especialização de que ainda pouco se fala nos cursos de graduação universitários, avançando ao refletir sobre a própria contribuição da arte na atuação do psicólogo, seja na clínica, seja em outros contextos, como um meio para trabalharmos com a (inter)subjetividade em uma concepção estética do humano.

Hoje a arteterapia não está mais restrita aos consultórios, revelando-se um valioso instrumento para intervenções também nas áreas da Psicologia social, escolar, organizacional, da saúde e hospitalar. O que se quer mostrar aqui é que a arte é um poderoso canal de expressão da subjetividade humana, que permite ao psicólogo e a seu cliente, seja ele um indivíduo, seja um grupo, acessar conteúdos emocionais e retrabalhálos através da própria atividade artística. Uma grande diversidade de temas, desde traumas e conflitos emocionais, aspectos das relações interpessoais em um grupo, expectativas profissionais, gênero e sexualidade, identidade pessoal e coletiva, entre outros, podem ser abordados pelo psicólogo através da arte. Ela é uma ferramenta que amplia as possibilidades de expressão, indo além da abordagem tradicional, que é baseada na linguagem verbal.

A mediação da arte na comunicação apresenta algumas vantagens, entre as quais a expressão mais direta do universo emocional, pois não passa pelo crivo da racionalização que acompanha o discurso verbal. Além disso, com a atividade artística, facilitamos o contato do sujeito com suas questões por um viés criativo, e não apenas dando forma a determinado conteúdo subjetivo, mas também podendo reconfigurá-lo em novos sentidos. O modo como esse processo acontece encontra diferentes explicações em função da perspectiva teórica considerada, como será analisado adiante, mas a ideia central é essa: a atividade criadora como um instrumento e a arte como um caminho de transformação subjetiva.

Como método de trabalho do psicólogo, a arteterapia poderá ser adaptada a diferentes objetivos, bem como sustentada sobre diferentes abordagens teóricas, cabendo ao psicólogo a escolha da linha com que mais se identifique. Neste artigo, serão enfocadas as abordagens consideradas principais e que foram as primeiras a marcar presença no desenvolvimento da arteterapia: psicanálise, junguiana, gestalt. Embora cada uma delas tenha seu modo próprio de trabalhar com o fazer criativo, todas reconhecem que a arte promove o autoconhecimento e potencializa a criatividade, habilidades essenciais ao desenvolvimento, tanto de um indivíduo como de um grupo com quem o psicólogo esteja trabalhando.

\section{Histórico da arteterapia}

Entre os anos 20-30, as teorias de Freud e Jung trouxeram as bases para o desenvolvimento inicial da arteterapia como campo específico de atuação, segundo descrevem Carvalho e Andrade (1995). Os autores relembram que Freud (1856-1939), ao analisar algumas obras de arte (por exemplo, o Moisés, de Michelangelo), observou que elas expressavam manifestações inconscientes do artista, considerando-as uma forma de comunicação simbólica, com função catártica. A ideia freudiana de que o inconsciente se expressa por imagens, tais como as originadas no sonho, levou à compreensão das imagens criadas na arte como uma via de acesso privilegiada ao inconsciente, pois elas escapariam mais facilmente da censura do 
que as palavras. Apesar desse grande achado, o próprio Freud não chegou a utilizar a arte como parte do processo psicoterapêutico.

Jung (1875-1961), ilustre discípulo de Freud, com quem posteriormente rompeu ao desenvolver sua própria teoria, a Psicologia analítica, foi quem propriamente começou a usar a linguagem artística associada à psicoterapia. Diferentemente de Freud, que considerava a arte uma forma de sublimação das pulsões, Jung considerava a criatividade artística uma função psíquica natural e estruturante, cuja capacidade de cura estava em dar forma, em transformar conteúdos inconscientes em imagens simbólicas (Silveira, 2001). Ele sugeria aos seus pacientes que desenhassem ou pintassem livremente seus sonhos, sentimentos, situações conflitivas, etc., analisando as imagens criadas por eles como uma simbolização do inconsciente individual e coletivo (Andrade, 2000). Jung utilizava o desenho livre para facilitar a interação verbal com o paciente e porque acreditava "na possibilidade de o homem organizar seu caos interior utilizando-se da arte" (Andrade, 2000, p.52).

Partindo dessas duas vertentes teóricas, o uso da arte como instrumento terapêutico foi progressivamente ganhando espaço. A educadora norte-americana Margareth Naumburg (1890-1983) pode ser considerada a fundadora da arteterapia, pois foi a primeira a sistematizá-la, em 1941 (Andrade, 1995, 2000). Seu trabalho é denominado Arteterapia de Orientação Dinâmica, e foi desenvolvido com base na teoria psicanalítica (Naumburg, 1966). Nessa perspectiva, as técnicas de arteterapia visam a facilitar a projeção de conflitos inconscientes em representações pictóricas, sendo esse material submetido à interpretação seguindo o modelo teórico proposto por Freud.

No Brasil, a história da arteterapia nasce na primeira metade do século passado entrelaçada com a psiquiatria e influenciada tanto pela vertente psicanalítica quanto pela junguiana. Estas encontram-se representadas respectivamente nas figuras de Osório Cesar (1895-1979) e Nise da Silveira (1905-1999), psiquiatras precursores no trabalho com arte junto a pacientes em instituições de saúde mental. Ambos contribuíram para o desenvolvimento de uma outra abordagem frente à loucura, contrapondo aos métodos agressivos de contenção vigentes na época (eletrochoque, isolamento) à possibilidade de expressão da loucura e de sua eventual cura através da arte. Conforme relata Silveira, nesse caminho alternativo, construiu-se um tratamento mais humano, com inegáveis efeitos terapêuticos na reabilitação dos pacientes, que promovia "a recuperação do indivíduo para a comunidade em nível até mesmo superior àquele em que se encontrava antes da experiência psicótica" (2001, p.19).

Em 1923, Osório Cesar já era estudante interno no Hospital Psiquiátrico de Juqueri, localizado em Franco da Rocha, região metropolitana de São Paulo, e, a partir de 1925, aí trabalhou como médico ao longo de 40 anos (Andriolo, 2003). Já em 1925, cria a Escola Livre de Artes Plásticas do Juqueri, e, em 1948, é o organizador da $1^{a}$ Exposição de Arte do Hospital do Juqueri, no Museu de Arte de São Paulo (Carvalho \& Andrade, 1995). Sobre seu trabalho de arte com psicóticos, o Dr. Osório publica, em 1929, sua obra principal, A Expressão Artística nos Alienados, na qual apresenta seu método de classificação e de análise de obras de arte de pacientes psiquiátricos. Andriolo (2003) considera a importância do pensamento de Osório Cesar, localizando-o no início da formação do campo da Psicologia da arte no Brasil, onde sua obra representaria um exemplo consistente de leitura freudiana de arte, embora hoje passível de crítica pelo reducionismo da obra artística a uma psicologia individual e patologizante, em detrimento dos seus aspectos históricos e sociais.

No que tange à história da arteterapia, Carvalho e Andrade destacam o papel de Osório Cesar pela contribuição que trouxe no plano teórico, ao articular os conceitos freudianos à análise da arte, considerando-o 
Ela considerava que a palavra arte trazia uma conotação de valor, de qualidade

estética, que não tinha em vista ao utilizar a atividade expressiva com seus pacientes (Silveira, 2001). "o precursor no Brasil da análise da expressão psicopatológica de doentes mentais" (1995, p.34). Na perspectiva psicanalítica clássica, Osório Cesar analisa a simbologia sexual presente nas produções artísticas de seus pacientes, compreendendo a obra de arte como uma representação dos desejos pessoais do autor, disfarçados nos elementos simbólicos presentes nas imagens (Cesar, 1944). Devemos levar em conta ainda a relevância do trabalho de Osório Cesar para a valorização da arteterapia, pois ele realizou mais de 50 exposições divulgando a expressão artística de doentes mentais, procurando, com isso, afirmar a dignidade humana dessas pessoas (Andrade, 2000). Em termos da prática, de acordo com Carvalho e Andrade, o seu método era baseado na espontaneidade e na crença de que "o fazer arte já propiciava a 'cura por si', por ser um veículo de acesso ao conhecimento do mundo interior" (1995, p.34).

A psiquiatra Nise da Silveira trabalhava no Centro Psiquiátrico D. Pedro II, em Engenho de Dentro, Rio de Janeiro. Em 1946, assumiu a Seção de Terapêutica Ocupacional, onde os pacientes realizam variadas atividades expressivas (sobretudo pintura e modelagem), dando-lhe uma nova orientação, pois, para ela, a terapia com arte não deveria ter a finalidade de distrair, mas de contribuir efetivamente para a cura dos pacientes. Em 1952, ela criou, na mesma instituição, o Museu de Imagens do Inconsciente, composto pelo acervo crescente das obras produzidas pelos internos, que conta com mais de 300.000 documentos plásticos, entre telas, papéis e esculturas. Desse modo, constituiu um rico campo de pesquisa, em que a prática realizada na Seção de Terapêutica Ocupacional era respaldada pelo estudo do valor terapêutico da atividade criadora, a partir da investigação das imagens arquivadas no Museu de Imagens do Inconsciente. Essa trajetória é narrada por ela no livro O Mundo Das Imagens (Silveira, 2001), no qual explica seu método e traz diversos exemplos de análise de obras de arte no processo psicoterapêutico de pacientes, em uma leitura junguiana.
Embora seja considerada uma pioneira na história da arteterapia no Brasil (Carvalho \& Andrade, 1995; Andrade, 2000), Nise da Silveira não aceitava essa denominação ao seu trabalho, preferindo designá-lo terapêutica ocupacional. Ela considerava que a palavra arte trazia uma conotação de valor, de qualidade estética, que não tinha em vista ao utilizar a atividade expressiva com seus pacientes (Silveira, 2001). Apesar disso, críticos de arte como Mário Pedrosa e outros que passaram a frequentar o Museu de Imagens do Inconsciente reconheceram ali "verdadeiras obras de arte", como analisa Frayze-Pereira (2003). Outros aspectos a embasar a crítica de Nise da Silveira à arteterapia é que esta se caracteriza pela intervenção do terapeuta, enquanto, na prática adotada em Engenho de Dentro, as atividades realizadas pelos pacientes eram absolutamente livres, suas criações davam-se espontaneamente a partir do material disponibilizado nos ateliers, sendo apenas acompanhadas por uma monitora, mas não dirigidas por ela. Nisso encontramos uma distinção não somente metodológica mas também teórica, pois Nise da Silveira, junguiana, refere-se especificamente à arteterapia desenvolvida por Margaret Naumburg, psicanalítica, na qual o paciente é "dinamicamente orientado", a partir da relação transferencial, a descobrir a significação de suas criações, um processo de interpretação que não ocorria na abordagem proposta por Nise da Silveira.

Para ela, a função terapêutica da arte era permitir a expressão de vivências não verbalizáveis por aqueles que se encontravam imersos no inconsciente, ou seja, em um mundo fora do alcance da elaboração racional, cabendo ao terapeuta a tarefa de "estabelecer conexões entre imagens que emergem do inconsciente e a situação emocional vivida pelo indivíduo" (2001, p.18). Nessa tarefa, apoiava-se sobretudo na psicologia analítica de Jung, de onde derivou uma das mais importantes abordagens em arteterapia, de cujos conceitos principais iremos tratar adiante. Para Nise da Silveira, 
as produções artísticas não somente trazem elementos esclarecedores acerca do processo psicótico (sobretudo quando as obras de um mesmo autor são examinadas em série, revelando temas recorrentes) mas também trazem um valor terapêutico em si mesmas, "pois davam forma a emoções tumultuosas, despotencializando-as, e objetivavam forças autocurativas que se moviam em direção à consciência, isto é, à realidade" (2001, p.17). Para os pacientes, a atividade criadora permitia não somente dar uma forma ao seu tumulto emocional mas também transformálo por meio dessa expressão.

Nise da Silveira destaca que a eficiência do tratamento através de atividades expressivas se revelou na diminuição da porcentagem de recaídas na condição psicótica e de reinternações de pacientes beneficiados por esse trabalho em Engenho de Dentro, especialmente quando os egressos continuaram com algum acompanhamento. Este foi viabilizado por ela com a criação da Casa das Palmeiras, em 1956, instituição pioneira no atendimento de pacientes em regime de portas-abertas.

O trabalho de Nise da Silveira inaugurou um novo olhar acerca da relação entre arte e loucura. Conforme analisa Frayze-Pereira, o Museu de Imagens do Inconsciente se constituiu, desde sua origem, como "um núcleo de pesquisa da esquizofrenia" (2003, p.198). No entanto, mais do que somente dar acesso à interioridade dos esquizofrênicos e levar as suas obras ao conhecimento do grande público, o autor destaca a importância do Museu na formação de um novo campo de sentidos, "que abre a passagem entre o hospício e o mundo das imagens, campo que articula Psicologia, arte e política numa trama cultural" (2003, p.198). Nesse campo, a arte não só é instrumento de transformação da realidade interna do esquizofrênico como também de sua realidade externa, à medida que sua expressão ganha o espaço do Museu: "na moldura de uma exposição legitimada pela cultura, a 'expressão marginal' certamente ganha o selo de 'obra de arte'. O marginal, o louco, o psiquiatrizado, torna-se artista e aos olhos do espectador, 'gênio'" (2003, p.204).

Embora os psiquiatras Osório César e Nise da Silveira sejam pioneiros no trabalho com terapias expressivas no Brasil, o desenvolvimento da arteterapia e sua sistematização no campo específico da Psicologia se deram posteriormente. Conforme descreve Andrade (2000), na construção desse campo, destaca-se Maria Margarida M. J. de Carvalho, que, em 1980, implantou o primeiro Curso de Arteterapia no Instituto Sedes Sapientae, em São Paulo. Ela é psicóloga clínica, foi professora do Instituto de Psicologia da USP e coordenadora, em 1995, do livro A Arte Cura? Recursos Artísticos em Psicoterapia. Outro marco destacado por Andrade foi a criação, em 1982, da Clínica Pomar, no Rio de Janeiro, coordenada por Angela Philippini, onde se oferece curso de formação em arteterapia de orientação junguiana. Já em 1990, outra abordagem entra no cenário da arteterapia brasileira, ao ser implantada uma especialização em arteterapia gestáltica por Selma Ciornai, no Sedes Sapientae. Desde então, a arteterapia vem crescendo cada vez mais, ganhando outros espaços além da clínica e também outras molduras teóricas, como a rogeriana, a antroposófica e a transpessoal, entre outras.

\section{Pressupostos fundamentais na arteterapia}

Embora possa ser desenvolvida a partir de diferentes referenciais teóricos, a arteterapia se define em todos eles por um ponto em comum: o uso da arte como meio à expressão da subjetividade. Sua noção central é que a linguagem artística reflete (em muitos casos melhor do que a verbal) nossas experiências interiores, proporcionando uma ampliação da consciência acerca dos fenômenos subjetivos (Ciornai, 1995). Liomar Quinto Andrade, que é psicólogo clínico e autor do livro Terapias Expressivas, publicação oriunda de sua tese de doutorado pela USP, 
define que "a expressividade ou a arte se torna um instrumento de trabalho quando combinada a um objetivo educacional ou terapêutico", apresentando como pressupostos fundamentais da arteterapia:

a) a expressão 'artística' revela a interioridade do homem, fala do modo de ser e visão de cada um e seu mundo. Esse ato revela um suposto sentido, e cada teoria e método em arte- terapia e terapia expressiva se apodera desse ato diferentemente, b) por intermédio desse 'fazer arte', expressar-se, o terapeuta pode estabelecer um contato com o cliente possibilitando a este último o autoconhecimento, a resolução de conflitos pessoais e de relacionamento e o desenvolvimento geral da personalidade (Andrade, 2000, p.18)

Acredito que o autor utilize aspas quando remete à arte porque, no âmbito da arteterapia, as atividades expressivas não têm uma finalidade estética, ou seja, a produção artística não é realizada e analisada por seu valor estético como obra de arte, ainda que muitas vezes seja posteriormente reconhecida como tal pelo público, a exemplo do desenho seguinte:

2. Referência aos artistas, em notícia sobre a exposição Raphael e Emygdio:

Dois Modernos no Engenho de

Dentro, realizada no Instituto Moreira

Salles, Rio de Janeiro, em 2012. A notícia foi publicada em 26/06/2012, pelo Estadão

(Recuperado em 07/08/2012, de http://www.estadao. com.br/noticias/ impresso,emygdiode-barros-eraphael-dominguesganham-exposicaono-ims, 905787,0 .

htm).

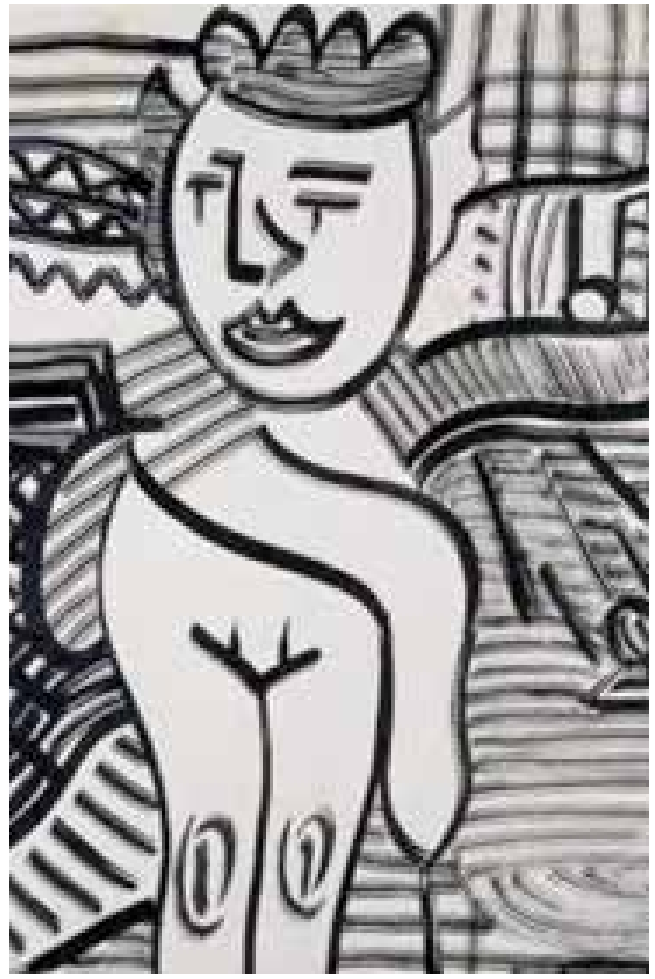

Nanquim sobre papel, 47,0 × 31,0 cm, 1948, por Raphael
Domingues (http://museuimagensdoinconsciente.org.br/ colecoes/raphael00.html\#)

O autor do trabalho, Raphael Domingues (1912-1979), foi um dos pacientes-artistas de Engenho de Dentro que participaram de importantes exposições, dentre as quais uma realizada em 1949, no Museu de Arte Moderna de São Paulo, cuja repercussão na imprensa e no meio artístico é examinada por Dionísio (2001). O autor lembra que, nessa ocasião, o crítico de arte Mário Pedrosa cria o termo arte virgem para designar os trabalhos dos nove participantes, então pacientes da Dra. Nise da Silveira. Entre eles, Raphael e Emygdio de Barros (1895-1986) são hoje vistos como grandes artistas esquizofrênicos ${ }^{2}$.

À parte a discussão sobre a qualidade artística ou não dos trabalhos produzidos em arteterapia, o importante para o psicólogo é que a atividade expressiva se torne um instrumento à expressão e à reflexão dos sujeitos. Como atividade terapêutica, o que aqui se pretende não é propriamente fazer arte, mas sim, exercitar a criatividade, proporcionar que no fazer criativo se produzam outros modos de objetivação e de subjetivação. Desse modo, ela pode ser utilizada como recurso no contexto da clínica, da educação, da comunidade, da saúde pública, das empresas, em intervenções na área de dificuldades físicas, cognitivas, emocionais e sociais junto a indivíduos, famílias, grupos sociais e equipes de trabalho. Uma característica comum às terapias com arte é que, por meio da vivência expressiva, o sujeito "pode dar-se conta do que de fato sente e, durante esse processo, pode verdadeiramente fazer algo que assim o represente e a ele faça sentido" (Andrade, 2000, p.33). Portanto, na arteterapia, o fazer artístico se constitui como mediação no processo de autoconhecimento e de (re) significação do sujeito acerca de si próprio e de sua relação com o mundo.

Outro ponto compartilhado entre as diferentes abordagens é o reconhecimento da função terapêutica inerente à própria atividade 
artística e diretamente ligada à criatividade. Para Ostrower, "criar é, basicamente, formar. É poder dar uma forma a algo novo", "é tanto estruturar quanto comunicar-se, é integrar significados e é transmiti-los" (2004, pp. 9,142). Assim, o sentido da arte como ferramenta para o psicólogo não se restringe à sua função meramente expressiva, mas amplia-se pelo poder transformador da arte como ação criadora. E aqui compreendo arte como um processo de formatividade, ideia desenvolvida pelo filósofo italiano Luigi Pareyson (1918-1991), que definiu a atividade artística como um formar, cujo resultado é um ser, uma forma inteiramente nova, pois a arte "é um tal fazer que, enquanto faz, inventa o por fazer e o modo de fazer" (1984, p.32).

Na perspectiva histórico-cultural em Psicologia, a atividade criadora é compreendida como um processo no qual o sujeito reorganiza diversos elementos de sua experiência, combinando-os de modo diferenciado e, com isso, produzindo o novo (Vygotski, 1990). Nessa atividade, ele parte do que está dado, do que é conhecido, reconfigurando-o em uma nova forma a partir da imaginação, o que culmina na “ objetivação do produto da imaginação, a qual, ao materializar-se na realidade, traz consigo uma nova força, que se distingue por seu poder transformador frente à realidade da qual partiu" (Zanella, Da Ros, Reis, \& França, 2003, p.44). Vygostki, na obra Psicologia da Arte (escrita entre 1924 e 1926), salienta a função transformadora dessa atividade, que extrai da vida o seu material, produzindo algo acima desse material, pois "a arte está para a vida como o vinho para a uva" (1998, p.307). Embora esse não seja um autor de referência na arteterapia, a ideia de que o fazer criativo é transformador perpassa esse campo.

Na visão de Ciornai, o propósito fundamental da arteterapia é resgatar a criatividade na vida, ou seja, contribuir para que o sujeito aprenda a "lidar criativamente com os limites que a vida Ihe impõe" (1995, p.59), transformando-se assim em artista da própria vida. Isso é possível porque a arte nos abre a uma "realidade alternativa" (1995, p.61), na qual o homem pode "perceber, figurar e reconfigurar suas relações consigo, com os outros e com o mundo" (1995, p.61). Portanto, no trabalho do psicólogo mediado pelo fazer artístico, destaco como princípios fundamentais a concepção da arte como atividade expressiva e criativa: não se trata apenas da expressão da subjetividade, da objetivação de emoções, sentimentos e pensamentos em uma forma artística (desenho, pintura, modelagem, etc.), mas especialmente da sua transmutação pela arte, da sua reconfiguração em novas formas e em outros sentidos, em um processo no qual, ao criar na arte, o sujeito se recria na vida.

\section{Arteterapia psicanalítica}

Margaret Naumburg foi a pioneira no trabalho com arteterapia em um viés psicanalítico, desenvolvendo a arteterapia de orientação dinâmica. Sua aproximação inicial com a arte, entretanto, deu-se na área da educação, juntamente à irmã Florence Cane, que era artista e professora de arte (por muitos anos trabalharam juntas na Walden School, fundada por Naumburg) e, enquanto Florence desenvolveu métodos de ensino para liberar a expressão artística, tornando-se pioneira na arte-educação, Margaret se baseou em suas conquistas para fazer da arte um instrumento terapêutico (Andrade, 2000).

Na visão de Naumburg, a expressão artística é como um espelho, que reflete diversas informações, estabelecendo uma ponte no diálogo entre consciente e inconsciente (Andrade, 1995). Baseada na concepção freudiana do determinismo do inconsciente, cujos pensamentos e sentimentos se expressariam mais em imagens do que palavras, como comprovado por Freud na 
teoria dos sonhos, Naumburg considera que a atividade pictórica favorece a projeção de conteúdos inconscientes, favorecendo, por uma via simbólica, a comunicação entre paciente e terapeuta.

As imagens produzidas no fazer artístico são assim abordadas como em um procedimento psicanalítico, podendo ser ligadas a conteúdos de sonhos, fantasias, medos, memórias infantis e conflitos atuais vividos pelo sujeito. Uma vez que geralmente as pessoas, ao iniciarem um processo psicoterapêutico, se encontram com o próprio discurso muito bloqueado devido às resistências, a arte vem a ser um canal que facilita a comunicação, pois, conforme Andrade, "através do uso da expressão gráfica ou plástica começam a desenvolver a verbalização ao explicar e falar a respeito de suas produções artísticas" (2000, p.73).

Naumburg trouxe como princípio básico da arteterapia psicanalítica o reconhecimento de que todo indivíduo, independentemente de possuir ou não um treinamento artístico, tem a capacidade de projetar seus conflitos interiores em formas visuais. Nessa abordagem, a interpretação da expressão artística acontece sempre na relação transferencial, na qual o sujeito é incentivado pelo terapeuta a descobrir por si mesmo o significado de suas produções, estimulando-se o uso da livre associação, a fim de que ele expresse em palavras os sentimentos e os pensamentos projetados nas imagens pictóricas. Segundo Naumburg, a arteterapia pode auxiliar na redução do tratamento e na diminuição da transferência negativa, pois "as imagens objetivadas atuam então como uma comunicação simbólica imediata que sobrepuja as dificuldades inerentes na linguagem verbal" (1991, p.389).

$\mathrm{Na}$ arteterapia psicanalítica, outro ponto fundamental é a concepção da arte como uma forma de sublimação, tal como postulado por Freud. A sublimação designa o processo no qual as pulsões são desviadas de seu objetivo original, de ordem sexual, e utilizadas em atividades culturais, tais como a criação artística ou a investigação intelectual, visando objetos socialmente valorizados (Laplanche \& Pontalis, 1998). A ideia de sublimação, aceita por Naumburg, é mais representativa no trabalho de arteterapia de Edith Krammer, artista, professora de arte e psicanalista nascida em Viena, Áustria, em 1916, e que emigrou para Nova York em 1938. A visão de Krammer diferencia-se da de Naumburg, porque ela não praticava a interpretação, "dando prioridade ao processo de fazer arte sem a necessidade de verbalização" (Andrade, 1995, p.45).

A ênfase de Krammer estava no valor terapêutico do processo criativo e do fazer artístico em si mesmo, que propõe a arte como terapia, em vez de uma psicoterapia que utiliza a arte como ferramenta (Ciornai, 2004). O fundamento de seu trabalho está no reconhecimento do papel da arte como sublimação, entendendo-se por sublimação a transformação dos impulsos antissociais, agressivos e sexuais em um ato socialmente produtivo, "de modo que o prazer produzido pelo resultado desse ato social substitui, pelo menos em parte, o prazer que a gratificação original teria proporcionado" (Andrade, 1995, p.45).

Na visão de Krammer, a criação artística é em si mesma terapêutica, porque contribui para o equilíbrio psíquico e o fortalecimento do ego, mediante a resolução do conflito entre forças contrárias (id $x$ superego), que encontram, via sublimação, uma possibilidade de síntese na atividade criadora. Ela definia o artista como alguém que "aprendeu a resolver, mediante a criação artística, os conflitos estabelecidos pela oposição entre as demandas dos impulsos e as demandas do superego" (Krammer, 1982, p.27). Nessa 
perspectiva, compreende-se que, na arte, se torna possível a expressão de desejos, impulsos, sentimentos e pensamentos que, muitas vezes, são inaceitáveis socialmente, sendo mais saudável encontrarem uma via de escape na arte do que serem recalcados, retornando na forma de sintomas. Assim, para Krammer, o papel do arteterapeuta, que deveria possuir também aptidões de artista e professor, era tornar disponível às pessoas esse valioso recurso: "O poder da arte de contribuir para o desenvolvimento de uma organização psíquica capaz de funcionar sob pressão sem fragmentar-se ou recorrer a medidas defensivas nefastas" (Krammer, 1971 como citado em Ciornai, 2004, p.28).

\section{Arteterapia junguiana}

A arteterapia junguiana desenvolve-se no Brasil tendo como principais referências o próprio Jung e o trabalho de Nise da Silveira. Nessa perspectiva, a função da atividade artística é mediar a produção de símbolos do inconsciente. Para Jung, "uma palavra ou uma imagem é simbólica quando implica alguma coisa além do seu significado manifesto e imediato" (1977, p.20), sendo que esse outro sentido remete ao inconsciente. Contudo, enquanto para Freud o inconsciente é formado por conteúdos reprimidos, relativos à história pessoal do indivíduo, Jung concebe, além do inconsciente pessoal, a existência do inconsciente coletivo, formado pelos instintos e pelos arquétipos. O autor o chama de coletivo, pois ele não é constituído de conteúdos individuais, "mas de conteúdos que são universais e aparecem regularmente" (2001, p.355).

Outra diferença é que, para Jung, "além de memórias de um passado longínquo, também pensamentos inteiramente novos e idéias criadoras podem surgir do inconsciente" (1977, p.38), já que lhe é inerente uma função criadora, que se manifesta nas imagens dos sonhos, das fantasias, nos mitos e na expressão plástica. Conforme salienta Silveira, tais produtos da função imaginativa do inconsciente são "auto-retratos do que está acontecendo no espaço interno da psique, sem quaisquer disfarces ou véus" (2001, p.85), sendo uma característica própria da energia psíquica transformar-se em imagem. Em decorrência disso, a abordagem junguiana em arteterapia não é baseada na interpretação das imagens como representações veladas do inconsciente, cujo sentido viria a posteriori, dependendo da verbalização do paciente. Ao contrário, Silveira coloca que o importante ao indivíduo é "dar forma, mesmo rudimentar, ao inexprimível pela palavra: imagens carregadas de energia, desejos e impulsos" (2001, p.86), nas quais "a libido poderá ser apreendida viva, e não esfiapada pelo repuxamento das tentativas de interpretação racionais" (2001, p.86).

Acerca da origem dessas imagens do inconsciente, que encontram uma via de expressão no fazer artístico em arteterapia, a Psicologia analítica distingue dois tipos, conforme descreve Silveira: a) imagens que representam emoções e experiências vivenciadas pelo indivíduo, originandose do inconsciente pessoal e b) imagens arquetípicas, originadas do inconsciente coletivo, que são de caráter impessoal, configurando-se a partir de disposições inatas, que formam a estrutura básica e as camadas mais profundas da psique. Segundo a autora, as imagens arquetípicas "configuram vivências primordiais da humanidade, semelhantes nos seus traços fundamentais" (2001, p.86), exprimindo, de diferentes modos em função da época e do lugar, os mesmos afetos e ideias básicos do ser humano.

Talvez o maior exemplo de imagens arquetípicas seja os mitos, cujo estudo por Jung foi de suma importância para o desenvolvimento da própria noção de arquétipo, a partir da sua constatação de que os mitos "encerram temas bem definidos 
que reaparecem sempre e por toda a parte" (2001, p.352). Os temas míticos, forjados a partir de imagens arquetípicas, expressam experiências fundamentais da humanidade (Silveira, 2001). Além dos mitos e dos sonhos, as próprias ideias delirantes eram vistas por Jung como representações arquetípicas. Seguindo essa linha, Silveira compreendia a própria condição psicótica como uma inundação do consciente por imagens arquetípicas, as quais ganhavam forma nas pinturas, nos desenhos e nas esculturas de seus pacientes. Suas produções artísticas apareciam então como símbolos do inconsciente, permitindo ao terapeuta uma visualização dos processos psíquicos ao mesmo tempo em que, ao paciente, a (re) experiência, isto é, a transformação desses processos.

Os símbolos são verdadeiros transformadores de energia psíquica, daí sua importância na arteterapia; conforme Silveira, "Jung compara os símbolos a dínamos que transformam uma modalidade de energia psíquica em outra" (2001, p.54). Assim, os símbolos expressos na arte não são vistos como simples projeção de conteúdos inconscientes, mas como mecanismos à sua transformação qualitativa, contribuindo para o equilíbrio psíquico. Nessa perspectiva, entende-se que, ao externalizar no papel o drama interior vivido de modo desordenado, o indivíduo não só dá forma a suas emoções, mas através disso "despotencializa figuras ameaçadoras" (Silveira, 2001, p.18).

3. Maria de Lourdes escreveu, ao lado de sua pintura: “Eu queria vir ao mundo, mas não achava um jeito.

Então vim em forma de árvore, que é um modo lindo e perfeito, por isso me transformei em árvore" (citado em Silveira, 2001, p.144). a metamorfose remete a mudança de forma, conservando-se a essência do ser metamorfoseado, que é abundante como metáforas nas artes, mas vivenciada como experiências reais nos delírios dos loucos. Um exemplo é o da metamorfose vegetal, recorrente em diversas imagens nas quais pacientes se retratavam na forma de árvore ou de flor.

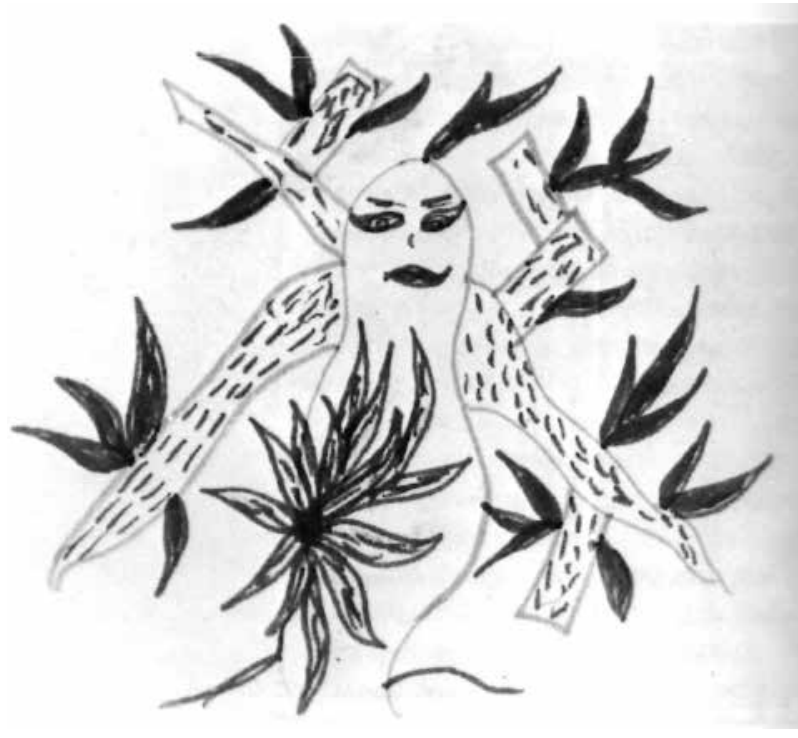

Hidrocor sobre papel, 22,0 × 29,0 cm, por Maria de Lourdes Simões (do livro O Mundo das Imagens, de Nise da Silveira)

Para Silveira, essas imagens evocam o mito de Dafne, ninfa grega que foi transformada em uma árvore para fugir ao assédio de Apolo. Ela entende que, na linguagem mítica, própria do inconsciente, esse tema estaria vinculado ao temor da mulher acerca da realização completa de seu ser feminino, representando, no caso da autora da imagem acima ilustrada, a sua dificuldade em estruturar-se subjetivamente como mulher ${ }^{3}$.

Existem inúmeras técnicas que podem ser usadas pelo psicólogo em um trabalho de arteterapia na linha junguiana, propondose atividades específicas ou simplesmente disponibilizando ao indivíduo diferentes materiais à sua escolha (papéis, giz pastel, tintas diversas, aquarela, argila, etc.). Embora 
Nise da Silveira trabalhasse apenas com a expressão livre e espontânea dos pacientes, na arteterapia, o psicólogo pode também estruturar as atividades expressivas a partir de alguns objetivos ou temas pertinentes ao caso em questão, visando com isso a auxiliar a pessoa em seu processo de individuação. Tal como postulado por Jung, a individuação designa o processo no qual um ser se torna realmente uma unidade, uma totalidade, pela integração consciente de seus vários aspectos inconscientes, manifestando a sua unicidade: "trata-se da realização de seu si-mesmo, no que tem de mais pessoal" (2001, p.355). O processo de individuação é o crescimento psíquico, o constante desenvolvimento da personalidade, no qual cada pessoa deve encontrar seu modo único de se realizar (Von Franz, 1977). Na arteterapia junguiana, o psicólogo acompanha a pessoa em seu caminho para a autorrealização, dialogando e procurando facilitar essa jornada através da arte.

Uma técnica muito utilizada na arteterapia junguiana é o desenho ou a pintura de mandalas. O termo mandala vem do sânscrito e significa círculo mágico, e designa "figuras geométricas formadas a partir do centro de um círculo ou de um quadrado, configurando um espaço sagrado" (Raffaelli, 2009, p.47). Na teoria junguiana, a mandala é um símbolo do self, isto é, do si-mesmo, representando ao mesmo tempo o centro e a totalidade psíquica (Jung, 2001).

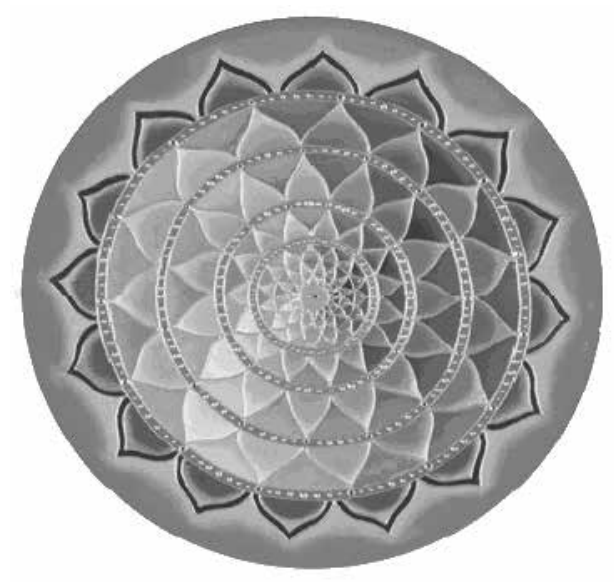

Mandala (www.mandalas.com)
A função terapêutica de desenhar mandalas está ligada à autodescoberta, pois elas registram o estado psíquico do indivíduo em diferentes momentos, representando, a partir de linhas, cores e formas, sua energia psíquica e a organização de seu mundo interno. A partir daí, podem proporcionar insights profundos, conduzindo a pessoa em sua jornada rumo ao self. Em seu livro autobiográfico, Memórias, Sonhos e Reflexões, Jung relata a importância das mandalas em sua própria vida profissional e pessoal:

Só quando comecei a pintar as mandalas vi que o caminho que seria necessário percorrer e cada passo que deveria dar, tudo convergia para um dado ponto, o do centro. Compreendi sempre mais claramente que a mandala exprime o centro e que é a expressão de todos os caminhos: é o caminho que conduz ao centro, à individuação (2001, p.174)

As mandalas podem auxiliar a "restabelecer o equilíbrio interior perdido" (Von Franz, 1977, p. 212), uma vez que desenhá-las contribui para a (re)orientação da energia psíquica em torno do centro ou self (circumambulação). Ao trabalharmos com arteterapia na perspectiva junguiana, devemos evitar o uso da interpretação, por isso, a melhor forma de fazer a leitura de uma mandala é pedindo à própria pessoa para entrar em contato com o que desenhou, procurando perceber e integrar os sentidos presentes naquela imagem.

\section{Arteterapia gestáltica}

A abordagem gestáltica em arteterapia foi desenvolvida por Janie Rhyne, que sistematizou-a no livro The Gestalt Art Experience, escrito em 1973 e publicado no Brasil com o título Arte e Gestalt: Padrões que Convergem (Rhyne, 2000). Nessa obra, ela articula conceitos da Psicologia da Gestalt a diversas técnicas que utilizam materiais artísticos, tanto no contexto psicoterapêutico 
quanto educacional, para trabalhar com indivíduos ou grupos. Sendo a Psicologia da Gestalt originalmente uma teoria da percepção, esse é um conceito central na arteterapia gestáltica, na qual a vivência artística tem como finalidade ampliar a percepção do sujeito sobre si mesmo.

Gestalt é uma palavra alemã que significa "forma, uma configuração, o modo particular de organização particular das partes individuais que entram em sua composição" (Perls, 1988, p.19). Rhyne utiliza o termo para se referir à percepção de uma configuração total, por exemplo, a pessoa perceber sua personalidade como um todo, cujas diversas partes formam, em seu conjunto, a realidade daquilo que ela é, lembrando que o todo é mais do que a simples soma de suas partes. Nessa abordagem, a função terapêutica do fazer artístico é a aquisição de insights sobre como percebemos, nas formas criadas, tanto o mundo como a nós mesmos. Tratase de um processo em que a arte promove awareness, termo chave na Gestalt-terapia, para o qual não há uma tradução exata em português, mas cujo sentido seria dar-se conta ou aperceber-se do que se passa consigo no momento vivido, levando a um ganho de consciência. Conforme define Rhyne:

A experiência gestáltica de arte, então, é o seu eu pessoal complexo fazendo formas de arte, envolvendo-se com as formas que você está criando como fenômenos, observando o que você faz, e, possivelmente, espera, percebendo por meio de suas produções gráficas não apenas como você é agora, mas também modos alternativos que estão disponíveis para que você possa se tornar a pessoa que gostaria de ser (2000, p.44)

Dessa forma, a vivência de criar arte promove a descoberta de sentimentos e de qualidades pessoais, auxiliando no desenvolvimento do potencial único de cada um, que no produto criado (desenho, pintura, escultura, poesia, etc.) pode reconhecer-se, ou seja, pode ver-se e também rever-se, vendo-se de uma nova forma ao visualizar possibilidades até então ignoradas. Por isso, Rhyne entende a atividade artística como um modo consciente de integração entre fantasia e realidade, que se encontram de maneira construtiva na obra criada. Esta constitui, então, uma ponte entre as realidades interna e externa, pela qual se expressariam mensagens enviadas pela pessoa para si própria. A compreensão de tais mensagens se baseia na percepção de inter-relações entre a forma do objeto criado na atividade artística e os processos subjetivos do criador, que assim toma conhecimento de aspectos seus até então desconsiderados, e, conforme Andrade, "tendo 'insights' e integrando seu passado no seu presente, desejo e realidade como um projeto de futuro" (2000, p.129).

Uma categoria central na arteterapia gestáltica é a vivência, que significa experienciar um evento, estando pessoal e emocionalmente envolvido nesse acontecimento, ou seja, é estar aqui-e-agora, como protagonista e observador do acontecimento em curso. Nesse sentido, a vivência de arte em Gestalt é um meio para o contato do sujeito consigo mesmo, definindo-se no conjunto formado por:

a) fazer formas artísticas, b) estar emocionalmente envolvido nas formas que estão sendo criadas como um evento pessoal, c) observar o que está sendo feito, e d) perceber através das produções realizadas não somente como a pessoa está neste momento, mas também maneiras alternativas possíveis para desenvolver-se seguindo modelos mais desejados por ela mesma (Andrade, 2000, p.131)

Nessa linha, a vivência artística não somente permite ao sujeito desvelar-se pelas formas criadas em modos de ser até então ignorados por ele mesmo mas ainda revelar-se, projetando-se por formas diversas em novos modos de ser-no-mundo. Trago aqui como exemplos desse processo arterapêutico dois desenhos (abaixo), extraídos de Rhyne. Eles foram feitos por Cyndy, uma assistente social, 
quando esta participou de um grupo de experiência gestáltica de arte, coordenado por Janie Rhyne, cujo tema central era ser mulher, que tinha como objetivo o contato das participantes com sua essência feminina:

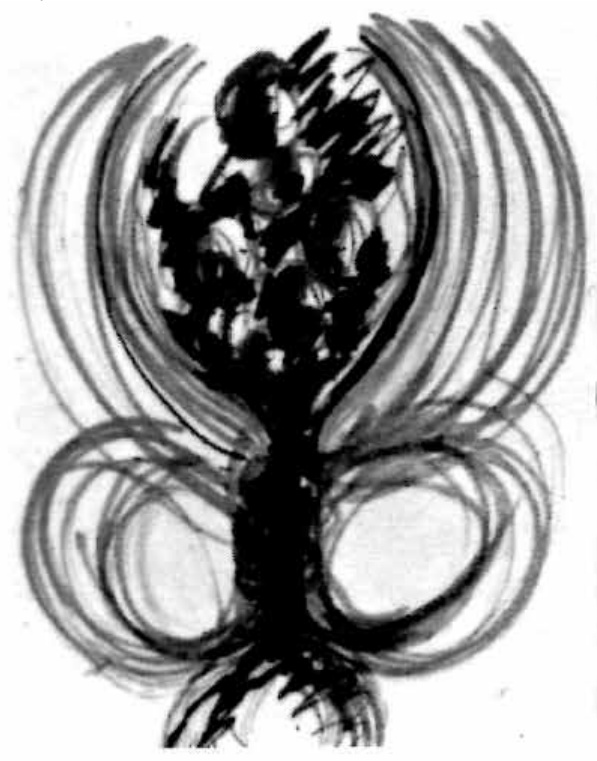

Eu quero

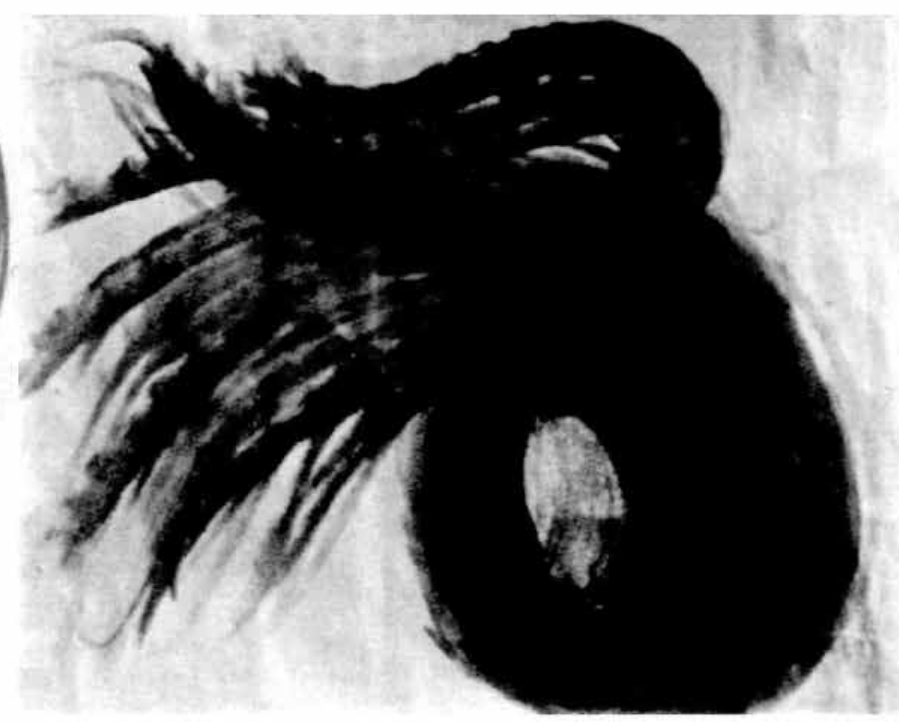

Quem sabe amanhã

Segundo Rhyne, os desenhos de Cyndy refletem "o processo universal de desejar, crescer, esforçar-se e alcançar o sentido completo da identidade única de cada um" (2000, p.110). Mas, para cada um deles, Cyndy escreveu um registro pessoal ${ }^{4}$ do modo como deu significado aos desenhos em função de seu processo vivencial. Como coloca Rhyne, as imagens criadas "não têm um significado particular por si mesmas; o modo como as percebemos dá-lhes significado" (2000, p.140). Assim, um recurso que pode ser usado em arteterapia gestáltica é associar a expressão escrita às atividades plásticas, como uma forma de dinamizar a awareness, pois os sentidos da mensagem visual poderão tornar-se mais claros para o próprio sujeito por meio da descrição que escreverá acerca de sua produção artística.

4. Em Eu quero, Cyndy escreve: "Eu quero, eu tento, eu tento, eu aperto, minha abertura não está aberta. Eu estou fechada, eu queimo, tentando. Tentando apertar e abrir. Eu quero o amanhã agora.

Eu não posso acontecer amanhã, eu aconteço agora. Somente" (citado por Rhyne, 2000, p.110).
No método desenvolvido por Rhyne, a abordagem dos trabalhos de arte pelo psicólogo deve respeitar em primeiro lugar os sentidos trazidos pela própria pessoa sobre sua criação, valorizandose a individualidade de cada ser humano. Do mesmo modo, Ciornai coloca que o papel do arteterapeuta gestáltico é acompanhar e guiar a busca do cliente, utilizando os processos artísticos para intensificar o contato do sujeito consigo mesmo, com os outros e com o mundo, de modo que a arte seja para ele uma fonte no aprendizado de si mesmo. E aprendendo uma nova forma de se expressar dentro de uma atividade artística, o sujeito poderá encontrar também novos caminhos em sua vida (Ciornai, 1995).

\section{Uma concepção estética do humano}

A partir da descrição da arteterapia em alguns de seus principais aspectos históricos, teóricos e metodológicos, vimos como a arte tem se constituído como um instrumento diferenciado de trabalho do psicólogo. Embora relativamente recente, é já amplo o campo da arteterapia, e por isso o panorama aqui oferecido mostra dele apenas um recorte possível, privilegiando as abordagens clássicas e, dentro delas, alguns dos autores e suas principais ideias. Para além das diferenças entre as vertentes aqui examinadas (psicanalítica, junguiana e gestáltica), constato que há uma certa visão 
de homem como ser criativo, compartilhada pelas diferentes vertentes, a qual estaria na base da arteterapia, perpassando por suas diversas molduras. Trata-se, a meu ver, de uma concepção estética do humano, visto como capaz de criar e de recriar-se, um ser em constante devir, sendo a arte um catalisador nesse processo, pois possibilita ao homem experimentar formas diferentes de se expressar e, em consequência, de ser no mundo.

Seja a atividade artística concebida como projeção do inconsciente na psicanálise, seja expressão do self na Psicologia analítica ou como função de contato na autopercepção dentro da gestalt-terapia, a arte se revela em todas elas como um meio de objetivação da subjetividade. O produto da criação artística é sempre um espelho que reflete e refrata de modo mais ou menos distorcido aquele que o criou, pois nele ganham forma seus desejos, emoções, sentimentos e ideias. Esse produto, como um objeto estético, pode ser compreendido como um quasesujeito, conceito formulado por Dufrenne para se referir ao reenvio constante entre a objetividade da obra e a subjetividade do autor, pois, quando o artista se coloca a criar, "é a si mesmo que ele descobre no seu fazer" (2008, p.135). Entretanto, a função terapêutica do fazer artístico apenas se inicia com essa autodescoberta, aprofundando-se à medida que, na atividade criadora, o sujeito também se redescobre em novas formas, podendo reinventar-se como outro.

Não seria essa reinvenção de si mesmo, ou seja, essa transformação pessoal, o objetivo final de qualquer processo psicoterapêutico?
Ora, na atividade artística, o sujeito encontra uma possibilidade concreta de expressar não só aquilo que ele é mas também o que ainda pode vir a ser, construindo na arte outros modos de objetivação e subjetivação e, a partir daí, reconstruindo-se na vida, a partir de um novo olhar sobre si mesmo e sobre o mundo. Isso ocorre porque a vivência da arte traz sempre uma abertura do eu ao outro; de acordo com Reis, "a experiência estética proporciona ao sujeito o contato com a alteridade, com o diferente, com o inesperado, com o novo, engajando o sujeito em uma forma de percepção diferente da cotidiana, uma percepção sensível e criativa" (2011, p.85).

Acredito que a noção da arte como uma ferramenta à reconstrução de si mesmo atravesse as diferentes práticas em arteterapia, porque, sem isso, ela teria apenas uma finalidade lúdica, e não terapêutica. Se $A$ arte cura?, como questionado no título do livro organizado por Carvalho, creio que essa cura não possa ser pensada desvinculada da função criadora que qualquer atividade artística deveria ter, quando apropriada como instrumento pela Psicologia. Independentemente do contexto específico de atuação do psicólogo, entendo que ele tenha um compromisso ético no sentido de contribuir para que os sujeitos se reconheçam como criadores, não só como atores sociais mas também como autores que podem participar criativamente na sociedade de que são parte. $\mathrm{Na}$ arteterapia, procuramos realizar isso na interface entre a Psicologia e a arte, pautados em uma concepção estética do sujeito, cuja própria vida pode ser transformada em uma obra de arte. 


\section{Alice Casanova dos Reis}

Doutora em Psicologia Social pela Universidade de São Paulo e Professora de Psicologia do CESUSC (Complexo de Ensino Superior de Santa Catarina), Florianópolis - SC - Brasil.

E-mail: alicecasanova@yahoo.com.br

Endereço para envio de correspondência:

Servidão Estrela Açoriana, 18. Cacupé. CEP: 88050-035. Florianópolis, SC.

Recebido 29/09/2012, 1a Reformulação 04/06/2013, Aprovado 29/08/2013.

\section{Referências}

Andrade, L. Q. (1995). Linhas teóricas em arte-terapia. In M. M. M. J. de Carvalho (Org.), A Arte Cura? Recursos artísticos em psicoterapia (pp. 39-54). Campinas, SP: Editorial Psy II.

Andrade, L. Q. (2000). Terapias expressivas. São Paulo: Vetor.

Andriolo, A. (2003). A "psicologia da arte" no olhar de Osório Cesar: leituras e escritos. Psicol.: Ciên. e Prof., 23(4), 74-81. doi: http://dx.doi.org/10.1590/S1414-98932003000400011

Carvalho, M. M. M. J. (1995). O que é arte-terapia. In M. M. M. J. Carvalho (Org.), A arte cura? Recursos artísticos em psicoterapia (pp. 23-26). Campinas, SP: Editorial Psy II.

Carvalho, M. M. M. J., \& Andrade, L. Q. A. (1995). Breve histórico do uso da arte em psicoterapia. In M. M. M. J Carvalho (Org.), A arte cura? Recursos artísticos em psicoterapia (pp. 27-38). Campinas, SP: Editorial Psy II.

Cesar, O. (1944, novembro). Como se Deve Compreender uma Obra de Arte. O Estado de S. Paulo, p. 4.

Ciornai, S. (1995). Arte-terapia: o resgate da criatividade na vida. In M. M. M. J Carvalho (Org.), A arte cura? Recursos artísticos em psicoterapia (pp. 59-63). Campinas, SP: Editorial Psy II.

Ciornai, S. (Org.) (2004). Percursos em arteterapia: arteterapia gestáltica, arte em psicoterapia, supervisão em arteterapia. São Paulo: Summus Editorial.

Dionísio, G. H. (2001). Museu de Imagens do Inconsciente: considerações sobre sua história. Psicol.: Ciênc. e Prof., 21 (3), 30-35. Recuperado em 31 julho, 2012, da PePSIC (Periódicos Eletrônicos em Psicologia): http://pepsic.bvsalud.org/

Dufrenne, M. (2008). Estética e filosofia (3a ed.). São Paulo: Perspectiva.

Frayze-Pereira. J. A. (2003). Nise da Silveira: imagens do inconsciente entre psicologia, arte e política. Estudos Avançados, 17(49), 197-208. doi: http://dx.doi.org/10.1590/ S0103-40142003000300012

Jung, C. G. (1977). Chegando ao inconsciente. In C. G. Jung \& M. L. von Franz (Orgs.). O homem e seus símbolos (M. L. Pinho, trad., pp. 18-103). Rio de Janeiro: Nova Fronteira.

Jung, C. G. (2001). Memórias, sonhos, reflexões (21a ed., A. Jaffé, Ed., D. F. Silva, trad.). Rio de Janeiro: Nova Fronteira.

Krammer, E. (1982). Terapia através del arte en una comunidad infantil. Buenos Aires: Kapelusz.

Laplanche, J., \& Pontalis, J. B. (1998). Vocabulário da psicanálise (3a ed., P. Tamen, trad.). São Paulo: Martins Fontes.

Naumburg, M. (1966). Dinamically oriented art therapy: Its principles and practice. Nova lorque: Grune-Stratton.

Naumburg, M. (1991). A arteterapia: seu escopo e sua função. In E. F. Hammer (Org.), Aplicações clínicas dos desenhos projetivos (pp. 388-392). São Paulo: Casa do Psicólogo.

Ostrower, F. (2004). Criatividade e processos de criação (18a ed.). Petrópolis, RJ: Vozes.

Pareyson, L. (1984). Os problemas da estética. São Paulo: Martins Fontes.

Perls, F. (1988). A abordagem gestáltica e testemunha ocular da terapia (2a ed., J. Sanz, trad.). Rio de Janeiro: LTC.

Raffaelli, R. (2009). Jung, mandala e arquitetura islâmica. Psicol. USP, 20(1), 47-66. Recuperado em 31 julho, 2012, de http:// www.revistasusp.sibi.usp.br

Reis, A. C. (2011). A experiência estética sob um olhar fenomenológico. Arquivos Brasileiros de Psicologia, 63(1), 75-86. Recuperado em 31 julho, 2012, de http://pepsic.bvsalud.org/ scielo.php?pid=S1809-52672011000100009\&script =sci_ arttext

Rhyne. J. (2000). Arte e gestalt: padrões que convergem (M. B. P. Norgren, trad.). São Paulo: Summus.

Silveira, N. (2001). O mundo das imagens. São Paulo: Ática.

Von Franz, M. L. (1977). O processo de individuação. In C. G. Jung \& M. L. von Franz (Orgs.), O homem e seus símbolos (M. L. Pinho, trad., pp. 158-229). Rio de Janeiro: Nova Fronteira.

Vygotski, L. S. (1990). La imaginación y el arte en la infancia. Madrid: Akal.

Vygotski, L. S. (1998). Psicologia da arte (P. Bezerra, trad.). São Paulo: Martins Fontes.

Zanella, A. V., Da Ros, S. Z., Reis, A. C., \& França, K. B. (2003). Concepções de criatividade: movimentos em um contexto de escolarização formal. Psicologia em Estudo, 8(1), 143-150. 